\title{
Use of SSR markers to study genetic polymorphism in members of the Ribes $L$. genus from the VNIISPK collection
}

\author{
Anna Pavlenko*, Maria Dolzhikova, Anna Pikunova, and Annastasiya Bakhotskaya \\ Russian Research Institute of Fruit Crop Breeding (VNIISPK), Zhilina, Orel, Russian Federation
}

\begin{abstract}
This study was the first time in Russia to carry out a large-scale (127 samples) assessment of the diverse gene pool of black currant and red currant, the study of intervarietal polymorphism between varieties of the Ribes L. genus from the VNIISPK collection. A cluster analysis of the genetic similarity of black currant varieties (53 varieties), red currant (73 varieties) and one gooseberry variety was performed using 14 SSR markers. Based on the data obtained, a dendrogram was built, in which a number of clusters with high bootstrap support (BS, \%) were distinguished. At $\mathrm{BS}>50 \%$, the coefficients of pairwise genetic similarity between varieties varied from 0.4 to 0.91 . The studied representatives of the Ribes genus merged into two main clusters of red currant and black currant. The blackcurrant cluster was joined by gooseberries. The SSR analysis method allows to reveal broad perspectives in the field of identifying varieties affiliation to species.
\end{abstract}

\section{Introduction}

Currant became known to people quite a long time ago. The first records of black currant were made in the 17th century in the United States by herbalists who drew attention to the medicinal properties of the shrub's fruits and leaves [1].

In wildlife conditions, all Ribes L. species are diploid $(n=8,2 n=16)$. There are varieties of 32-chromosomal currant - gooseberry hybrids (Kroma, Joshta, Johine, Johelina, Rike, etc.), created in the middle of the 20th century. In many programs, polyploidy has been very effectively used by breeders, but diploid level is more often used to obtain commercially successful varieties [2].

For 2020, the Russian state register of breeding achievements includes 205 varieties of blackcurrant, 42 varieties of redcurrant and 10 varieties of white currant approved for usage [3].

A large collection of currant varieties is available in the All-Russian Research Institute of fruit crops breeding. It contains over 100 varieties of blackcurrant (Ribes nigrum) and more than 80 varieties of red currant (Ribes rubrum).

\footnotetext{
* Corresponding author: tolpekina@vniispk.ru
} 
At the present stage, an important tool for establishing the genetic structure and diversity of the gene pool are molecular genetic methods, including those based on the use of microsatellite markers. Microsatellite markers (Simple Sequence Repeat, SSR) is a modern type of DNA markers, which due to its multi-allelism, high reproducibility, and polymorphicity is used for practical purposes, including verification of kinship, control of purebred livestock, etc.

The first microsatellite markers for currant genus members were developed by Scottish scientists [4]. The project "RIBESCO" carried out by European scientists is aimed at a deeper study of Ribes L. genus representatives, as well as the gene pool preservation in Northern Europe using the polymorphism analysis of microsatellite loci. 846 varieties of the Ribes genus were analyzed from various collections, including red and white currant varieties, black currant and gooseberry varieties [5].

In the work of Palmieri et al. in 2013 [6], a study was carried out using 10 microsatellite loci on 91 varieties of certain currant species (Ribes). Unique multilocus profiles were obtained for 87 study objects. This study confirmed that even a relatively small volume of SSR markers can be effectively used for the study of currant's genetic diversity, which is confirmed by research of other scientists and scientific groups [7-9].

Belarusian scientists under the leadership of O. Y. Urbanovich studied the variability of microsatellite loci in representatives of the Ribes L. genus. A genetic diversity study of 86 varieties from the collection of the Ribes genus cultivated in Belarus, Russia, Ukraine, Lithuania, Sweden and other countries using 8 SSR-markers was conducted. Research results indicate high variability of microsatellite sequences' alleles of black currant, red currant and gooseberry varieties under study [10].

For the first time in Russia, genotyping of microsatellite loci of black currant (Ribes nigrum) was performed by specialists from VNIISPK. A high polymorphism of 14 microsatellite loci in 27 black currant varieties has been revealed, unique and rarely encountered alleles have been identified. The obtained results helped to get a unique multilocus profile for all studied varieties [11].

In our study, an extensive assessment (on 127 varieties) of the diverse gene pool of black currant (Ribes nigrum) and red currant (Ribes rubrum) was given based on polymorphism of 14 microsatellite loci from the VNIISPK collection. Intervariety polymorphism was studied, genetic similarity between varieties was determined, and the pedigree forms of red and black currant forms were checked. The obtained results will help to select a set of informative DNA markers for effective collection use and work with genetic resources.

\section{Materials and methods}

To study the genetic diversity of the study's objects, 14 microsatellite loci were analyzed (g1-K04, g1-M07, g1-L12, g1-A01, e1-O01, e1-O21, gr2-J05, g2-J08, g2-L17, g2-H21, g2G12, e3-B02, Cra-489, Cra-531). Research materials were varietal samples from the collection of the All-Russian Research Institute of Fruit Crop Breeding (VNIISPK): 73 varieties of red currant (Ribes rubrum), 53 black currant varieties (Ribes nigrum) and 1 gooseberry variety (Ribes uva-crispa).

According to the method of Doyle J.J. et al. [12] DNA isolation of young leaves was performed by CTAB-method. PCR - analysis was carried out in a reaction mixture with a volume of $20 \mu \mathrm{l}$, containing 1xPCR buffer solution, $200 \mu \mathrm{m}$ of nucleotides, $2 \mu \mathrm{m}$ of upstream primer, $2 \mu \mathrm{m}$ of downstream primer, $0.3 \mathrm{un}$. of Taq DNA polymerase and $10 \mathrm{ng}$ DNA. 
The amplification reaction was carried out according to the following algorithm: preliminary denaturation -5 minutes at $95^{\circ} \mathrm{C}$ temperature; denaturation -30 seconds at $95^{\circ}$ $\mathrm{C}$; annealing primer -30 seconds at the temperature selected for each marker; DNA synthesis -30 seconds at $72^{\circ} \mathrm{C}$ (total 30 cycles); last phase - elongation for-10 minutes at $72^{\circ} \mathrm{C}$.

ABI prism Genetic Analyzer 3010 was used to separate DNA fragments. Different in size and fluorescent label, PCR products of several loci have been assembled into a single multiplex (analysis was carried out on ABI prism Genetic Analyzer simultaneously). Peak Scanner Software_v01 [13] was used to fix the primary results.

Based on the obtained data to determine genetic diversity, a dendrogram was constructed and the Jacquard similarity coefficient was calculated using the PAST program. Dendrogram was compiled by the method of cluster analysis UPGMA (unweighted pair group method with arithmetic mean) using the Jacquard coefficient and bootstrap analysis.

To detect allele frequency (an allele with a frequency less than 0.2 was considered rare), the probability of identity according to the Hardy-Weiberg law (HW) and the probability of identity in the sibs analysis of Sib P (ID), the GENECAP - Microsoft Excel macro was used [14].

\section{Results and discussion}

With the amplification of 14 microsatellite loci, 36 varieties had no amplification in at least one of the loci (amplification was repeated twice).

In almost every genotype at a particular locus, a maximum of two fragments were identified, but in separate loci, three fragments were amplified in some samples. Black currant varieties: Strelets, Kupaliniai, Buraya sladkaya, Chereshnyevaya, Nimfa, Yadrenaya, Lentyai - locus G1-M07; Sokrovische, Strelets - G2-H21; Zaglyadyenie, Charodei, Fortuna, Dobryi Dzin, Ben Sares, Oasis, Chudnoye mgnovyenie, Kreolka, Kipiana - GR2-J05; Monisto - G1-L12. Red currant varieties: Belaya krupnaya - Cra531; Orlovchanka, Konstantinovskaya, Nadezhda and gooseberry variety Jupiter - e3-B02; Marmyeladnitsa -g2-G12; Nenaglyadnaya, Podarok leta — e1-O21; Nadezhda — g2-J08; Svetlitsa, Tatyanina, Uralskaya krasnaya $\square$ g1-L12.

There is evidence of amplification of more than two alleles in separate microsatellite loci in diploids in the literature, and this is due to the duplication of microsatellite loci on the same or on different chromosomes [15].

Based on the data found, we analyzed the genetic similarity of the Ribes L. genus representatives from the collection of VNIISPK. A dendrogram was constructed, which clearly shows the extent of differences and similarities between the samples studied. Figure 1 shows the bootstrap support values (BS, \%) for those nodes where BS was more than $50 \%$. For other nodes, bootstrap is relatively low, which does not allow to determine these branchings as reliably justified. 


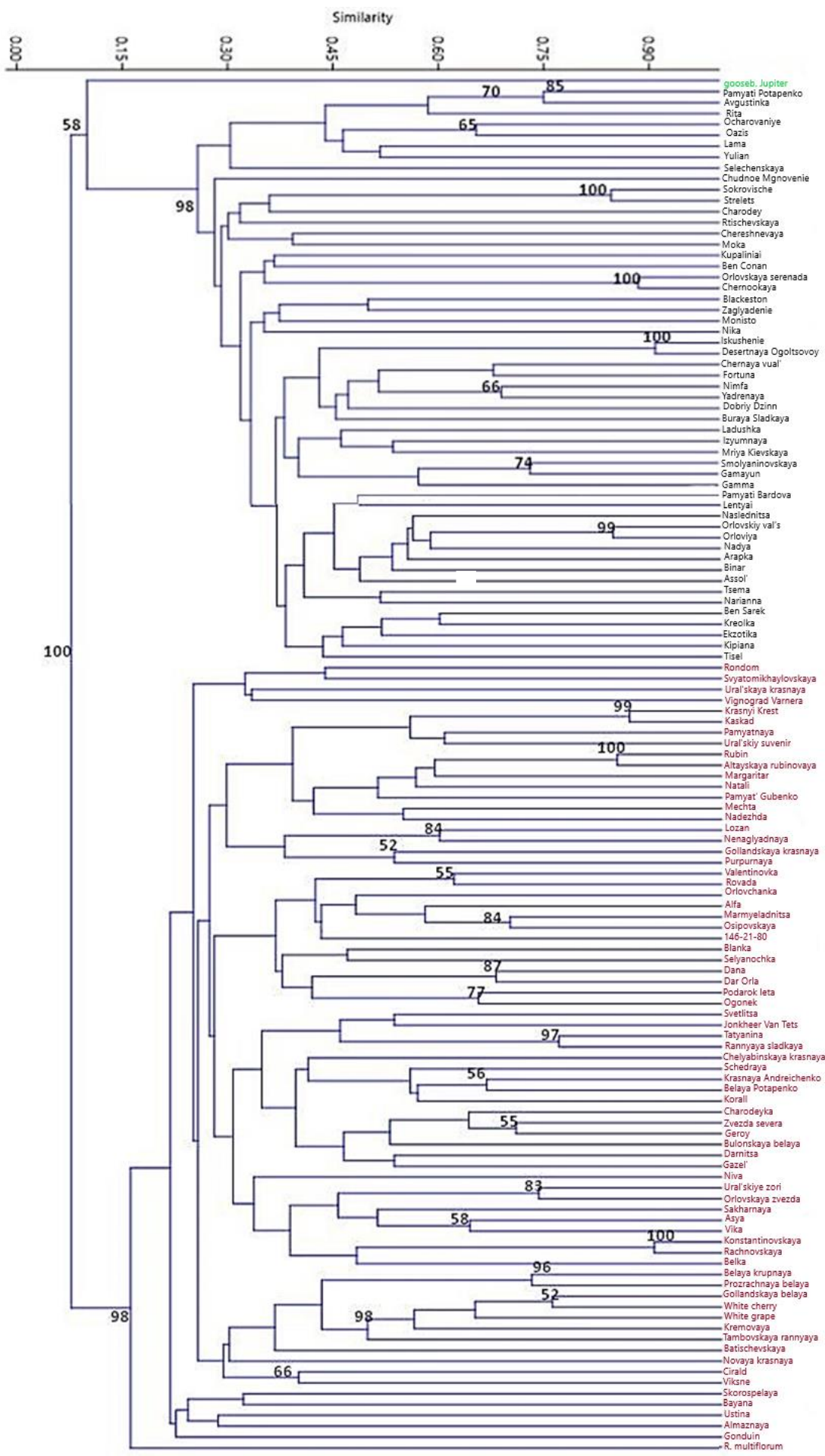

Fig. 1 Dendrogram of genetic similarity of black currant, red currant and gooseberry based on the obtained SSR analysis results 
The studied varieties of the Ribes genus were divided into two base clusters of red currant and black currant. On the dendrogram, the latter was joined by Jupiter gooseberry variety with a similarity coefficient of 0.1 with the bootstrap index $58 \%$. Such addition has also been observed in other works, for example, according to P. Lanham et al. [16] a number of hybrids of currants and gooseberries are located in the group of black currant varieties. In a foreign study of M. Cavanna et al. (2009) [17], species of the currant genus (blackcurrant, redcurrant, gooseberry, blackcurrant and gooseberry hybrids) have been used. According to the analysis of 13 polymorphic microsatellite loci, a genetic similarity dendrogram of 41 currant genus members' samples was constructed. Varieties formed 3 main groups. The first group includes the Missouri variety, which is the only specimen belonging to $R$. missouriense; the second group was divided into two subgroups and includes all red currant varieties, third group contains 2 subgroups, one of which is joined by gooseberry varieties, and the second contains black currant varieties. These varieties have been grouped in cluster analysis according to their geographical origin.

In the work of Mezhnina (2017), a genetic diversity dendrogram of 86 Ribes genus varieties was constructed and described using 8 SSR-markers. Several clusters are distinguished in the dendrogram. Common gooseberry and red currant varieties are located at a considerable genetic distance forming two separate clusters with high bootstrap support indicators. Possessing a unique composition of alleles by studied loci, alpine currant (Ribes alpinum), golden currant (Ribes aureum) and jostaberry (Ribes $\times$ nidigrolaria) are located at a great genetic distance from the cultural varieties of black currant. However, in this study, gooseberry varieties create a cluster more distant from currant representatives.

In our studies, the black currant cluster combined at a distance of 0.25 , but with high $98 \% \mathrm{BS}$; the red currant cluster combined at a higher genetic distance $(0.16)$ with a high bootstrap support of $98 \%$, which indicates a greater varieties' diversity; it was also the most numerous in terms of the number of formed intra-species clusters.

The species of $R$. multiflorum red currant joined the red currant cluster at a distance of 0.16 -; this indicates its difference from all analyzed red currant varieties. The obtained values of pairwise similarity coefficients at BS $>50 \%$ ranged from 0.4 to 0.91 for all varieties. In the works of domestic researchers, such as Mezhnina (2017), genetic distances between samples vary from 0.08 to 0.84 , and in the works of Pikunova (2015), genetic pairwise similarities coefficients range from 0.11 to 0.95 . In a foreign study by Cavanna et al. (2009), the genetic distance ranged from 0.00 , indicating the presence of synonyms, to 0.97 for different species of the same genus.

Konstantinovskaya and Rachnovskaya varieties are combined within the redcurrant cluster with maximum bootstrap support of $100 \%$ and at close genetic distance (similarity coefficient 0,9 ); their original forms are unknown. At a slightly greater distance $(0.87)$, the following varieties were combined: Red Cross (Vishnevaya $\times$ Belyi vinograd) and Cascad (seedling from open pollination of Diploma variety), (BS 99\%); Rubin and Altaiskaya rubinovaya (Faya plodorodnaya, open pollination) BS 100\%, 0.85 similarity coefficient. Tatianina (origin unknown) and Rannyaya sladkaya (Chulkovskaya $\times$ Laturnais) were combined at a distance of 0.77 with high $97 \%$ BS. Varieties with a lower $52 \%$ BS but at close 0.76 distance were combined into one group: Weisse Hollandische (descendant of common currant) and White cherry (descendant of common currant). Uralskiye zori (Faya plodorodnaya, open pollination) and Orlovskaya zvezda (Rote Spatlese $\times$ Minnesota) combined at a distance of 0.74 with $83 \%$ BS. Belaya krupnaya (origin unknown) and Prozrachnaya belaya (descendant of common currant) have also clustered with high BS $96 \%$, but at a longer distance 0.73 . Zvezda severa (descendant of common currant) and Geroy (descendant of common cherry currant) combined into a cluster at a distance of 0.71 with BS 55\%, Osipovskaya (Rote Spatlese $\times$; Minnesota) and Marmeladnitsa (Rote Spatlese $\times$ Prominent) - at 0.7 distance with BS 84\%. Dana and Dar Orla clustered 
with a high bootstrap support rate (87\%), both varieties descended from the cross-breeding of Rote Spatlese $\times$ Jonkheer Van Tets, at a distance of 0.68. Krasnaya Andreychenko (Krasnyi krest, open pollination) and Belaya Potapenko (Krasnyi krest $\times$ Krasnaya Sibiryachka) combined at a distance of 0.67 with BS 56\%. Podarok leta (Rote Spatlese $\times$ Jonkheer Van Tets) and Ogonyok (Rote Spatlese $\times$ Jonkheer Van Tets) clustered separately at close distance of 0.65 with BS 77\%; Asya (Chulkovskaya $\times$ Maarses Prominent) and Vika (Chulkovskaya $\times$ Red Lake) had a BS value of $58 \%$ and a distance of 0.64 , Valentinovka (Rote Spatlese $\times$ Jonkheer Van Tets) and Rovada (Faya plodorodnaya $\times$ Rote Spatlese) - BS 53\%, at a distance of 0.62. Lozan (origin unknown) and Nenaglyadnaya (Vishnevaya $\times$ (Chudesnaya $\times$ Gollandskaya krasnaya) $)$ clustered at a medium distance $(0,6)$ - BS $84 \%$. Gollandskaya krasnaya (hybrid of red currants and R. petracum sin carpaticum) and Purpurnaya (Rote Spatlese, open pollination) $-\mathrm{BS} 52 \%$ at a distance of 0.54 . Long distance $(0,4)$ - Ciralt (Cirvya Pistes $\times$ r.altissimum), and Viksne (from sowing Varshevich currant seeds) with BS $66 \%$.

Thus, the red currant cluster of 17 groups with high bootstrap -support contains two with a clear genotype kinship according to the pedigree data, three has a common originator, and in the other 12 there is no explicit kinship found as pedigrees are not clear (at least one or both parents unknown).

The blackcurrant cluster contains several groups with quite high bootstrap -support: black currant varieties Iskushenie (v.1163 × Chudesnitsa) and Desertnaya Ogoltsovoy (1163-7-80 $\times$ Dachnitsa) combined at a distance of 0.91 with BS $100 \%$. Also with BS $100 \%$ - Orlovskaya serenada (Yershistaya $\times$ Minai Shmyryev) and Chernookaya (Binar $\times$ Orlovskiy val's) at a distance of 0.88 . Sokrovische (5-67-2 $\times$ Nestor Kozin) and Strelets (Selechenskaya 2, open pollination) with BS $100 \%$ at a distance of 0.85 . Orlovskiy val's (Lentyai $\times$ Yershistaya) and Orlovia (Brodtorp open pollination) varieties combined with a high BS 99\% and a high similarity ratio (0.85). Pamyati Potapenko (Agrolesovskaya $\times$ Brodtorp) and Avgustinka (Minai Shmyrev $\times$ Ojebyn) black currant varieties combined at 0.75 distance with BS $85 \%$, this group was joined by Rita (Seedling of Golubka $\times$ Lepaan Musta) with a high BS 70\% at 0.57 . Smolyaninovskaya (Iziumnaya $\times 42-7$ ) and Gamayun (Katyusha $\times$ Pamyat' Vavilova) with BS $74 \%$ at a distance of 0.73 ; Nimfa (Uvertyura $\times$ Katyusha) and Yadrenaya (3-78-3 $\times$ Lubimitsa Altaya) - BS 66\% at a distance 0.69; Ocharovaniye (v.11-68 $\times$ Ekzotika) and Oazis (v. 1146, open pollination) at a distance of 0.65 . Thus, 8 groups were distinguished in the cluster of blackcurrants: four had a common originator, remaining collectible varieties groups it had no genetic similarity confirmation due to no found matches by parent forms or originators.

\section{Conclusion}

A dendrogram was built based on the study of SSR loci polymorphism, reflecting the genetic similarity of the Ribes genus representatives. Dendrogram clustering is consistent with taxonomic classification. Adding gooseberries to the black currant group according to DNA polymorphism has been observed earlier, including our works using RAPD analysis [18].

The study of the resulting allele flow through the studied varieties' pedigrees suggests that the varieties grouping within large clusters is sometimes supported by pedigree data; however, in most cases, due to the absence of pedigrees (in the case of unknown origin) or their incompleteness (one parent is known), it is not possible to explain clustering by pedigrees' data. The blackcurrant cluster combined four groups of varietal specimens with common parent forms: Iskushenie and Desertnaya Ogoltsovoy, Orlovskaya serenada and Chernookaya, Orlovskiy val's and Orlovia, Ocharovanie and Oazis VNIISPK breeding - 
varieties. In our analysis, the rest of the groups showed no genetic similarity despite their similar origin, for example, Arapka (1163-7-80 (Belarusskaya sladkaya $\times$ Sunderbun II) $\times$ 1448-14-20 (762-5-82 × Dachnica) and Gamma (762-5-82 $\times$ Ekzotika). Perhaps this is due to a large genetic diversity of varietal specimens and the number of loci studied proved insufficient, microsatellite analysis showed only small areas of the genome. The blackcurrant cluster was joined by the gooseberry variety Jupiter (Afrikanets $\times$ Grossular) with a similarity coefficient of 0.1 .

The most numerous cluster of red currant united 17 groups. In two groups there is a distinct genotype kinship according to pedigree data: varieties Dana and Dar Orla, Podarok leta and Ogonek - these varieties resulted from the crossbreeding of Rote Spatlese $\times$ Jonkheer Van Tets. Also these varieties have one originator - VNIISPK, Oryol, Russia. For the rest, no explicit kinship was found due to unclear pedigrees (one or both parents unknown). A study using SSR - markers allowed the study of inter-variety polymorphism.

\section{References}

1. J. Janick, J.N. Moore, Fruit Breeding, 2, 477 (1997)

2. Pomology. Currant, 4, 468 (2009)

3. State register of selection achievements admitted to use. Plants'varieties, 1 (2020)

4. R. Brennan, L. Jorgensen, M. Woodhead, J. Russell, Molecular Ecology Notes, 2(3), 327 (2002).

5. K. Antonius, S. Karhu, H. Kaldmäe, G. Lacis, R. Rugenius, D. Baniulis, A. Gunnarsson, Plant Genetic Resources, 10(1), 70 (2012)

6. L. Palmieri, M.S. Grando, M. Sordo, M. Grisenti, S. Martens, L. Giongo, Establishment of molecular markers for germplasm management in a worldwide provenance Ribes Collection, 6(3), 165 (2013)

7. V. Laucou, T. Lacombe, F. Dechesne, R. Siret, J.P. Bruno, M. Dessup, T. Dessup, P. Ortigosa, P. Parra, C. Roux, S. Santoni, D. Varès, J.P. Péros, J.M. Boursiquot, P. This. Theor Appl Genet, 122(6), 1233 (2011)

8. S.M. Potts, Y. Han, M.A. Khan, M.M. Kushad, A.L. Rayburn, S.S. Korban, Plant Mol Biol Rep, 30, 827 (2012)

9. S. Vilanova, J.P. Manzur, J. Prohens, Mol. Breeding, 30(4), 647 (2012)

10. O.A. Mezhnina, O.Yu. Urbanovich, Herald of the National Science Academy of Belarus, 3, 45 (2017)

11. A.V. Pikunova, S.D. Knyazev, A.Yu. Bakhotskaya, A.A. Kochumova, Agricultural biology, 50(1), 46 (2015)

12. J.J. Doyle, J.L. Doyle, Focus, 8(12), 13 (1990)

13. Peak ScannerTM Software Version 1.0. Part Number 4382253 Rev. A 12 (2006)

14. M.J. Wilberg, B.P. Dreher, Molecular Ecology Notes, 4(4), 783 (2004)

15. Z. Galli, G. Haláss, E. Kiss, L. Heszky, J. Dobránszki. Horticult. Sci., 40(7), 1974 (2005)

16. P.G. Lanham, R.M. Brennan, C. Hackett et al. Theoret. Appl. Genetics, 90(2), 166 (1995)

17. M. Cavanna, D.T. Marioni, G.L. Beccaro, G. Bounous. Microsatellite-based evaluation of Ribes spp. Germplasm, Genome, 52(10), 839 (2009) 
18. A.V. Pikunova, E.V. Martirosyan, S.D. Knyazev, N.N. Ryzhova, Ecological genetics, 9(2), 34 (2011) 